\title{
Three-dimensional hollow-structured binary oxide particles as an advanced anode material for high-rate and long cycle life lithium-ion batteries
}

Deli Wang ${ }^{\mathrm{a}, *}$, Huan He ${ }^{\mathrm{a}}$, Lili Han ${ }^{\mathrm{b}, \mathrm{c}}$, Ruoqian Lin ${ }^{\mathrm{b}, \mathrm{d}}$, Jie Wang ${ }^{\mathrm{a}}$, Zexing Wu ${ }^{\mathrm{a}}$, Hongfang Liu ${ }^{\mathrm{a}}$, and Huolin L. Xin ${ }^{\mathrm{b}, *}$

${ }^{a}$ Key laboratory of Material Chemistry for Energy Conversion and Storage (Huazhong University of Science and Technology), Ministry of Education, Hubei Key Laboratory of Material Chemistry and Service Failure, School of Chemistry and Chemical Engineering, Huazhong University of Science and Technology, Wuhan, 430074, P.R. China

${ }^{\mathrm{b}}$ Center for Functional Nanomaterials, Brookhaven National Laboratory, Upton, NY 11973 , USA

${ }^{\mathrm{c}}$ School of Materials Science and Engineering, Tianjin University, Tianjin 300072, P.R. China

${ }^{\mathrm{d}}$ Department of Materials Science and Engineering, Stony Brook University, Stony Brook, NY, 11794, USA

\section{Abstract}

Transition metal oxides are among the most promising anode candidates for next-generation lithium-ion batteries for their high theoretical capacity. However, the large volume expansion and low lithium ion diffusivity leading to a poor charging/discharging performance. In this study, we developed a surfactant and template-free strategy for the synthesis of a composite of $\mathrm{Co}_{\mathrm{x}} \mathrm{Fe}_{3-\mathrm{x}} \mathrm{O}_{4}$ hollow spheres supported by carbon nanotubes via an impregnation-reductionoxidation process. The synergy of the composite, as well as the hollow structures in the electrode materials, not only facilitate $\mathrm{Li}$ ion and electron transport, but also accommodate large volume expansion. Using state-of-the-art electron tomography, we directly visualize the particles in 3-D, where the voids in the hollow structures serve to buffer the volume expansion of the material. These improvements result in a high reversible capacity as well as 
an outstanding rate performance for lithium-ion battery applications. This study sheds light on large-scale production of hollow structured metal oxides for commercial applications in energy storage and conversion.

Keywords: transition metal oxides; hollow structures; lithium ion battery; electron tomography

\section{Introduction}

With the ever-increasing demand for high-performance and long cycle life lithium-ion batteries (LIBs), numerous types of anode materials are being investigated intensively, such as carbon [1] and [2], metal oxides [3] and [4], metal alloys [6] and [7] and sulfides [8]. Among the various anode materials, transition metal oxides have attracted significant attention because of their remarkably high theoretical capacities $\left(>700 \mathrm{mAh} \mathrm{g}^{-1}\right)$, double the capacity of commercially used graphite carbon anodes [9], [10] and [11]. This high capacity is achieved mainly through the conversion reaction, in which more than one lithium atom can be accommodated per transition metal cation, as opposed to one lithium atom per transition metal cation for intercalation compounds [12]. However, one of the limitations of transition metal oxide anode materials is the large volume change during lithiation/delithiation as well as the low lithium diffusivity, which can lead to electrode pulverization, subsequently resulting in low columbic efficiency and poor cycling stability [13] and [14]. Optimizing electrode structures to withstand a large volume expansion and shorten the $\mathrm{Li}^{+}$diffusion length, is a critical design rule for oxide anodes [15]. For example, mesoporous peapod-like $\mathrm{Co}_{3} \mathrm{O}_{4} @$ carbon nanotube arrays [16], $\mathrm{Co}_{3} \mathrm{O}_{4}$ nanowire array films [17], and hollow-structured $\mathrm{Co}_{3} \mathrm{O}_{4}[18]$ have been synthesized; they show high anodic performance as well as high cyclic stability. The other strategy is to incorporate carbon-based materials in the nanocomposites, such as carbon nanotubes [19], mesoporous carbon [20], and graphene [21] to enhance the 
electrical conductivity and thereby the electrochemical properties. Among them, carbon nanotubes are one dimensional nanomaterials, while graphene is belong to two dimensional nanomaterials. They have been classified by a leading candidate for a variety of advanced nanostructure with superior performance and widely used in hybrid anodes [22], [23] and [24].

Recently, binary metal oxides such as $\mathrm{Co}_{\mathrm{x}} \mathrm{Mn}_{3-\mathrm{x}} \mathrm{O}_{4}$ array [25], $\mathrm{Co}_{3} \mathrm{~V}_{2} \mathrm{O}_{8}$ multilayered nanosheets [10], $\mathrm{NiCo}_{2} \mathrm{O}_{4}$ hollow spheres [26], and ordered macroporous $\mathrm{CoFe}_{2} \mathrm{O}_{4}$ [27] have been prepared and exhibit high performance due to their enhanced electrical/ionic conductivity, and mechanical stability [25]. Relative to the other structures, hollow structures provide short and continuous paths for Li ion diffusion; the porous structure not only enlarges the surface area, but also leaves space to accommodate the volume change during the charge/discharge processes. Most of the previous reports on hollow structured materials were based on soft/hard template methods [28], [29], [30], [31], [32], [33], [34], [35], [36] and [37], which require lengthy steps and are not easily scaled industrial applications, due to the consumption of costly templates. Herein, we report a one-pot, two-step method for the synthesis of hollow structured binary metal oxides, $\mathrm{Co}_{\mathrm{x}} \mathrm{Fe}_{3-\mathrm{x}} \mathrm{O}_{4}(\mathrm{x}=2,1.5,1)$, supported on multiwall carbon nanotubes (MWCNTs). This method does not consume any foreign templates. The three-dimensional (3D) hollow structured $\mathrm{Co}_{\mathrm{x}} \mathrm{Fe}_{3-\mathrm{x}} \mathrm{O}_{4} / \mathrm{MWCNT}(\mathrm{x}=2,1.5)$ spheres exhibited excellent lithium storage capacity, good rate capability, and desirable cycling stability compared with $\mathrm{Co}_{3} \mathrm{O}_{4} / \mathrm{MWCNT}$ and $\mathrm{Fe}_{2} \mathrm{O}_{3} / \mathrm{MWCNT}$. This work provides a new strategy for the fabrication of hollow structured binary oxides for applications in largeformat lithium-ion batteries.

\section{Experimental}

\section{Material Synthesis}

The 3D hollow $\mathrm{Co}_{\mathrm{x}} \mathrm{Fe}_{3-\mathrm{x}} \mathrm{O}_{4} / \mathrm{MWCNT}(\mathrm{x}=2,1.5$ 1) material with $\mathrm{Co}$ :Fe nominal ratio of 2:1, 1:1 and 1:2 was synthesized via an "impregnation-reduction-oxidation" process. For example, 
in a typical synthesis of $\mathrm{Co}_{2} \mathrm{FeO}_{4} / \mathrm{MWCNT}$, Multiwall carbon nanotubes (MWCNTs) were first purified and dried before use. $210 \mathrm{mg}$ of $\mathrm{CoCl}_{2} \cdot 6 \mathrm{H}_{2} \mathrm{O}$ and $88 \mathrm{mg} \mathrm{FeCl} \cdot 4 \mathrm{H}_{2} \mathrm{O}$ and 120 mg of MWCNT were dissolved in 30ml ultrapure water. Afterwards, the solution was experienced ultrasonic and magnetic stirring at $60{ }^{\circ} \mathrm{C}$, and then evaporated into thick slurry and dried at $40{ }^{\circ} \mathrm{C}$ for 12 hours. The powder was grinded in agate mortal and then reduced in a tube furnace under flowing $\mathrm{H}_{2}$ at $350^{\circ} \mathrm{C}$ for $3 \mathrm{~h}$ to obtain $\mathrm{Co}_{2} \mathrm{Fe} / \mathrm{MWCNT}$ nanoparticles. Finally, the sample was heat-treated in an open air at $350{ }^{\circ} \mathrm{C}$ with a slow heating rate of $1{ }^{\circ} \mathrm{C}$ $\min ^{-1}$ to obtain $\mathrm{Co}_{2} \mathrm{FeO}_{4}$ hollow spheres.

\section{Material characterization}

Powder X-ray diffraction (XRD) was performed by using an X'Pert PRO diffractometer, and diffraction patterns were collected at a scanning rate of $4{ }^{\circ} \mathrm{C} \mathrm{min}^{-1}$. Thermal gravimetric analysis (TGA) was conducted on TA-500 TGA instrument at a heating rate of $10{ }^{\circ} \mathrm{C} \mathrm{min}{ }^{-1}$. X-ray photoelectron spectroscopy (XPS) data were obtained using an AXIS-ULTRA DLD600W Instrument. ADF-STEM tomographic images were obtained using 200 and $300 \mathrm{keV}$ field-emission S/TEMs.

\section{Electrochemical measurements}

Electrochemical measurements were carried out in CR 2032 coin cells assembled in an argonfilled glove box with lithium metal as the anode. The working electrode is comprised of active material, carbon black (super-p) and polymer binder (polyvinlidene fluoride; PVDF) in a weight ratio of 85:5:10, and $\mathrm{Cu}$-foil was selected as the current collector. The all electrodes of active materials loading were about $1.5-2 \mathrm{mg} \mathrm{cm}^{-2}$. The two electrodes were separated by Celgard 2320 and electrolyte was $1.0 \mathrm{M} \mathrm{LiPF}_{6}$ in a 1:1 ratio of EC (Ethylene carbonate): DEC (Diethylene carbonate). The cells cycling and rate performance were tested in the voltage window from 0.05 to $3.0 \mathrm{~V}$ on a NEWARE battery tester at room temperature. Cyclic 
voltammetry $(\mathrm{CV})$ was performed on a $\mathrm{CHI} 760 \mathrm{E}$ electrochemical working station at a scan rate $0.1 \mathrm{mV} \mathrm{s}^{-1}$. Electrochemical impedance spectroscopy (EIS) measured on the coin cell was performed with an Autolab PG302N electrochemical workstation in the frequency range from $100 \mathrm{kHz}$ to $0.01 \mathrm{~Hz}$ at open circuit potential with an ac perturbation of $10 \mathrm{mV}$.

\section{Results and discussion}

The synthesis procedure for hollow structured $\mathrm{Co}_{\mathrm{x}} \mathrm{Fe}_{3-\mathrm{x}} \mathrm{O}_{4} / \mathrm{MWCNT}(\mathrm{x}=2,1.5,1)$ comprises two steps (Figure S1). The first step involves forming solid alloy particles by using the "impregnation-reduction" method. In the second step, the solid alloy particles are converted into hollow structures by oxidation in air, based on the Kirkendall effect [38]. The successful transformation of a metal alloy into spinel oxides was verified by XRD patterns (Figure S2). Mono-metallic cobalt and iron oxides were also prepared for comparison (Figure S3). The mass loading of metal oxides on carbon support was measured via thermogravimetric analysis (TGA) (Figure S4 and S5).

The morphology and microstructure of the $\mathrm{Co}_{1.5} \mathrm{Fe}_{1.5} \mathrm{O}_{4} / \mathrm{MWCNT}$ spheres were characterized using Z-contrast annular dark-field scanning transmission electron microscopy (ADF-STEM), bright-field TEM, and electron tomography respectively, and the corresponding images and three-dimensional (3-D) reconstructions shown in Figure 1. The images show that the synthesized particles are submicron spheres with an average diameter of $220 \mathrm{~nm}$ (Figure 1a, b and Figure S6a). All spheres exhibit a hollow structure with a rough surface and with a cavity diameter ranging from $100 \mathrm{~nm}$ to $200 \mathrm{~nm}$. Furthermore, $\mathrm{Co}_{2} \mathrm{FeO}_{4} / \mathrm{MWCNT}$ and $\mathrm{CoFe}_{2} \mathrm{O}_{4} / \mathrm{MWCNT}$ also have the similar hollow structure (Figure S6b and S6c). Figure 1c and supplementary Movie 1 shows the consecutive cross-sectional images of the as-prepared $\mathrm{Co}_{1.5} \mathrm{Fe}_{1.5} \mathrm{O}_{4}$ particle through the 3-D reconstruction of the nanoparticle, it clearly visualizes the internal void space in the nanoparticles, formed due to the Kirkendall effect during oxidation. The void dramatically increases the particles' surface to volume ratio. 
The SAED pattern comprising of well resolved sets of concentric rings indicates the materials are polycrystalline (Inset of Figure 1b). The elemental distribution of the $\mathrm{Co}_{1.5} \mathrm{Fe}_{1.5} \mathrm{O}_{4}$ particle was obtained by spatially resolved electron energy loss spectroscopy (EELS). Figure 1c shows the elemental mapping and the corresponding EELS O-K, Fe- L2,3 and Co-L2,3 edge for a $\mathrm{Co}_{1.5} \mathrm{Fe}_{1.5} \mathrm{O}_{4}$ hollow sphere, which further confirmed the mixed metal oxide structure. All the evidences above suggest that a hollow structured Co-Fe binary oxide particle was successfully synthesized.

The cyclic voltammograms (CVs) curves of $\mathrm{Co}_{2} \mathrm{FeO}_{4} / \mathrm{MWCNT}$ for the first five cycles is shown in Figure 2a. For the first cycle, a well-defined irreversible reduction peak is observed at around $0.78 \mathrm{~V}$, which can be ascribed to the $\mathrm{Co}_{2} \mathrm{FeO}_{4}$ to metal and the subsequent formation of a solid electrolyte interface (SEI) film [39] and [40]. The peak position is located between pure $\mathrm{Co}_{3} \mathrm{O}_{4} / \mathrm{MWCNT}$ and $\mathrm{Fe}_{2} \mathrm{O}_{3} / \mathrm{MWCNT}$, which are at about 0.88 and $0.6 \mathrm{~V}$, respectively (Figure S7a and b, Supporting Information). The broad anodic peak at around 1.8 $\mathrm{V}$ is likely ascribed to the oxidation reactions of $\mathrm{Co}$ and $\mathrm{Fe}$ to $\mathrm{Co}_{3} \mathrm{O}_{4}$ and $\mathrm{Fe}_{3} \mathrm{O}_{4}$. In the second cathodic scan, two peaks appear at around $0.91 \mathrm{~V}$ and $1.34 \mathrm{~V}$, which can be attributed to the reduction of the bimetallic oxide to mono metal by referencing the $\mathrm{CV}$ curves of $\mathrm{Co}_{3} \mathrm{O}_{4}$ and $\mathrm{Fe}_{2} \mathrm{O}_{3}$. The peak intensity decreases significantly and shifts in the positive direction in the second cycle. The peak intensity and position remain unchanged in the following cycles, indicating highly reversible electrochemical reactions of the electrode material. Figure $2 \mathrm{~b}$ presents the discharge/charge profiles of the $\mathrm{Co}_{2} \mathrm{FeO}_{4} / \mathrm{MWCNT}$ electrode for the first five cycles at a current density of $0.1 \mathrm{~A} \mathrm{~g}^{-1}$. The first discharge plateau is located at $0.92 \mathrm{~V}$, which is lower than that on $\mathrm{Co}_{3} \mathrm{O}_{4} / \mathrm{MWCNT}$ electrode $(1.1 \mathrm{~V})$ and slightly higher than that on $\mathrm{Fe}_{2} \mathrm{O}_{3} / \mathrm{MWCNT}$ electrode (0.9 V) (Figure S7c, Supporting Information). The initial discharge capacities of $\mathrm{Co}_{2} \mathrm{FeO}_{4} / \mathrm{MWNCT}$ is $1582 \mathrm{mAh} \mathrm{g}^{-1}$, but a relative low charge capacity of 887 $\mathrm{mAh} \mathrm{g}^{-1}$ is achieved, leading to an initial Coulombic efficiency of around $56 \%$. The 
irreversible capacity loss may be caused by the decomposition of electrolytes and the SEI formation on the surface of the electrode materials [41] and [42], which are common to conversion reaction metal oxides anode. The low initial Coulombic efficiency could also attributed to the low lithium storage capacity and large initial irreversible capacity loss of MWCNT in the composites [43] and [44], which is tested to be only about $36 \%$ at $0.2 \mathrm{~A} \mathrm{~g}^{-1}$ (Figure S8, Supporting Information). Similar results have also been found for the $\mathrm{Co}_{1.5} \mathrm{Fe}_{1.5} \mathrm{O}_{4} / \mathrm{MWCNT}$ and the $\mathrm{CoFe}_{2} \mathrm{O}_{4} / \mathrm{MWCNT}$ electrodes (Figure S9, Supporting Information).

The long term cycling performance of $\mathrm{Co}_{\mathrm{x}} \mathrm{Fe}_{3-\mathrm{x}} \mathrm{O}_{4} / \mathrm{MWCNT}(\mathrm{x}=2,1.5,1)$ electrodes at a current density of $1 \mathrm{~A} \mathrm{~g}^{-1}$ is shown in Figure 2c. It is apparent that $\mathrm{Co}_{2} \mathrm{FeO}_{4} / \mathrm{MWNCT}$ and $\mathrm{Co}_{1.5} \mathrm{Fe}_{1.5} \mathrm{O}_{4} / \mathrm{MWCNT}$ demonstrate better cyclic retention than that of $\mathrm{CoFe}_{2} \mathrm{O}_{4} / \mathrm{MWCNT}$. The capacity of $\mathrm{Co}_{2} \mathrm{FeO}_{4} / \mathrm{MWNCT}$ and $\mathrm{Co}_{1.5} \mathrm{Fe}_{1.5} \mathrm{O}_{4} / \mathrm{MWCNT}$ electrodes slightly decayed in the initial 20 cycles, and then increased gradually, which was a common phenomenon for transition metal oxides anode materials [45], [46], [47] and [48]. After 500 cycles, the reversible capacity of $\mathrm{Co}_{2} \mathrm{FeO}_{4} / \mathrm{MWNCT}$ and $\mathrm{Co}_{1.5} \mathrm{Fe}_{1.5} \mathrm{O}_{4} / \mathrm{MWCNT}$ retained as high as 1233 and $1027 \mathrm{mAh} \mathrm{g}^{-1}$, respectively. However, $\mathrm{CoFe}_{2} \mathrm{O}_{4} / \mathrm{MWCNT}$ electrode exhibits very poor cycle stability, the capacity decreased gradually to $483.3 \mathrm{mAh} \mathrm{g}^{-1}$ after 200 cycles. It is noteworthy that the cycling performance of $\mathrm{Co}_{2} \mathrm{FeO}_{4} / \mathrm{MWNCT}$ and $\mathrm{Co}_{1.5} \mathrm{Fe}_{1.5} \mathrm{O}_{4} / \mathrm{MWCNT}$ is much better than that of pure $\mathrm{Co}_{3} \mathrm{O}_{4} / \mathrm{MWCNT}$ and $\mathrm{Fe}_{2} \mathrm{O}_{3} / \mathrm{MWCNT}$ electrode (Figure S11, Supporting Information). Furthermore, the Coulombic efficiency rapidly increases from about $50 \%$ for the first cycle to above $90 \%$ after two cycles and stabilized at nearly $100 \%$ thereafter, indicating fast ion and electron transport in the hollow structured electrodes.

Electrochemical impedance spectroscopy (EIS) was conducted to elucidate the relationship between the electrochemical performance and electrode kinetics of the different cells. Figure $2 \mathrm{~d}$ shows the Nyquist plots of three fresh coin cells using $\mathrm{Co}_{2} \mathrm{FeO}_{4} / \mathrm{MWCNT}$, 
$\mathrm{Co}_{1.5} \mathrm{Fe}_{1.5} \mathrm{O}_{4} / \mathrm{MWCNT}$ and $\mathrm{CoFe}_{2} \mathrm{O}_{4} / \mathrm{MWCNT}$ as electrode materials. It can be seen clearly that the all the three cells share a common feature with a depressed semicircle in high frequency $\left(\mathrm{R}_{\mathrm{ct}}\right)$ and a linear tail in low frequency region. For an equivalent circuit model and the corresponding fitted impedance parameters shown in Figure S10. The diameter of the semicircle for $\mathrm{Co}_{2} \mathrm{FeO}_{4} / \mathrm{MWCNT}\left(\mathrm{R}_{\mathrm{ct}}=82 \Omega\right)$ and $\mathrm{Co}_{1.5} \mathrm{Fe}_{1.5} \mathrm{O}_{4} / \mathrm{MWCNT}$ electrodes $\left(\mathrm{R}_{\mathrm{ct}}=\right.$ $116 \Omega$ ) were much smaller than that of $\mathrm{CoFe}_{2} \mathrm{O}_{4} / \mathrm{MWCNT}\left(\mathrm{R}_{\mathrm{ct}}=160 \Omega\right)$, indicating the $\mathrm{Co}_{1.5} \mathrm{Fe}_{1.5} \mathrm{O}_{4} / \mathrm{MWCNT}$ and $\mathrm{CoFe}_{2} \mathrm{O}_{4} / \mathrm{MWCNT}$ electrode exhibited better charge transfer performance and excellent conductivity. The electrical conductivity of the materials is deteriorated with increasing of iron content, which is probably the reason for the poor cycling performance of $\mathrm{CoFe}_{2} \mathrm{O}_{4} / \mathrm{MWCNT}$ electrode. Obviously, after cycling, the diameter of the semicircle for the hollow structured $\mathrm{Co}_{1.5} \mathrm{Fe}_{1.5} \mathrm{O}_{4} / \mathrm{MWCNT}$ electrode $\left(\mathrm{R}_{\mathrm{ct}}=61.5 \Omega\right)$ decreased compared with the fresh cell, indicating the charge transfer resistance decreased apparently after 5 cycles (Figure 2e).

Figure 3a shows the rate performance of $\mathrm{Co}_{1.5} \mathrm{Fe}_{1.5} \mathrm{O}_{4} / \mathrm{MWCNT}$ electrode at current densities ranging from 0.2 to $8 \mathrm{~A} \mathrm{~g}^{-1}$. It is clear that the $\mathrm{Co}_{1.5} \mathrm{Fe}_{1.5} \mathrm{O}_{4} / \mathrm{MWCNT}$ electrode exhibits an exceptionally high rate capability and especially notable is the discharge capacities of 706 and $567.3 \mathrm{~mA} \mathrm{~g}^{-1}$ at rather high current densities of 5 and $8 \mathrm{~A} \mathrm{~g}^{-1}$, respectively. Furthermore, when the current density was restored to $0.2 \mathrm{~A} \mathrm{~g}^{-1}$, the capacity could be recovered to $1140 \mathrm{mAh} \mathrm{g}^{-1}$, which is higher than that of initial capacity. The capacity increase can probably attributed to the decrease of the reaction resistance on $\mathrm{Co}_{1.5} \mathrm{Fe}_{1.5} \mathrm{O}_{4} / \mathrm{MWCNT}$ electrode after cycling (Figure 2e). The current density dependence of the discharge capacity in Figure $3 \mathrm{~b}$ further indicates the good rate capability of $\mathrm{Co}_{1.5} \mathrm{Fe}_{1.5} \mathrm{O}_{4} / \mathrm{MWCNT}$ electrode, which is much better than that of pure $\mathrm{Co}_{3} \mathrm{O}_{4} / \mathrm{MWCNT}$ and $\mathrm{Fe}_{2} \mathrm{O}_{3} / \mathrm{MWCNT}$ electrodes (Figure S7d, Supporting Information). The hollow structured $\mathrm{Co}_{\mathrm{x}} \mathrm{Fe}_{3-\mathrm{x}} \mathrm{O} 4 / \mathrm{MWCNT}(\mathrm{x}=2,1.5)$ electrodes herein exhibit superior long-tem cycling performance even at high current density 
of $5 \mathrm{~A} \mathrm{~g}^{-1}$ (Figure 3c). The reversible capacities of 413.8 and $487.3 \mathrm{mAh} \mathrm{g}^{-1}$ were delivered on $\mathrm{Co}_{2} \mathrm{FeO}_{4} / \mathrm{MWCNT}$ and $\mathrm{Co}_{1.5} \mathrm{Fe}_{1.5} \mathrm{O}_{4} / \mathrm{MWCNT}$ electrodes after 1000 cycles with a Coulombic efficiency nearly $100 \%$ after the $15^{\text {th }}$ cycle. To the best of our knowledge, there are few reports on transition-metal oxides anodes capable of cycling up to 1000 cycles, and the cycling stability and rate performance are significantly higher than most previously reported cobalt-based oxide materials [27], [49] and [50].

The remarkable lithium storage capability of $\mathrm{Co}_{2} \mathrm{FeO}_{4} / \mathrm{MWCNT}$ and $\mathrm{Co}_{1.5} \mathrm{Fe}_{1.5} \mathrm{O}_{4} / \mathrm{MWCNT}$ electrodes are likely related to the unique hollow structure and the synergistic effects of $\mathrm{Co}$ and $\mathrm{Fe}$ in the composites. The porous structure facilitates $\mathrm{Li}$ ions transport in the electrode, resulting in excellent rate performance and cycling capacity retention at high current density [51]. The interior hollow structure provides open spaces to buffer the large volume expansion, thus alleviating the pulverization of the particles. Ex-situ Z-contrast STEM imaging and tomography were employed to monitor the 3-D morphological and structural changes of the $\mathrm{Co}_{1.5} \mathrm{Fe}_{1.5} \mathrm{O}_{4} / \mathrm{MWCNT}$ particles at different lithiation/delithiation stages during the first cycle. As shown in Figure 4a, the cutoff voltage of each sample was chosen at $0.65 \mathrm{~V}, 0.05 \mathrm{~V}, 1.65 \mathrm{~V}$, and $3.0 \mathrm{~V}$, respectively, corresponding to the electrode was at stages of half-discharge, full-discharge, half-charge, and full-charge. The as-prepared $\mathrm{Co}_{1.5} \mathrm{Fe}_{1.5} \mathrm{O}_{4} / \mathrm{MWCNT}$ particles show a hollow structure (Figure $4 \mathrm{~b}$ ). At half-discharged state, the voids in the particle were gradually occupied by $\mathrm{Li}_{2} \mathrm{O}$ and $\mathrm{Co}(\mathrm{Fe})$. The high-resolution Zcontrast STEM images in Figure 4c shows the formation of misfit dislocations and disruption of the oxide lattice at the early phase of the conversion reaction. Similar phenomenon was reported on Nickel oxide nanosheet anode materials [52]. Figure 4d presents the STEM images of the $\mathrm{Co}_{1.5} \mathrm{Fe}_{1.5} \mathrm{O}_{4} / \mathrm{MWCNT}$ particle at the full-discharged state. It was observed that more void space were occupied compared with the half-discharged state (later, we will show the 3D tomographic reconstructions). While after being fully charged, the porous structure 
could partially recover to its pristine solid form, however with a fraction of the materials remain nanoporous (Figure 4e). The nanoporosity likely facilitates ionic/electronic transport in the subsequent discharge/charge cycles. The morphology preservation of $\mathrm{Co}_{1.5} \mathrm{Fe}_{1.5} \mathrm{O}_{4}$ particles could be further verified by SEM and TEM (Figure S12, Supporting Information). It is noted that the original texture of $\mathrm{Co}_{1.5} \mathrm{Fe}_{1.5} \mathrm{O}_{4} / \mathrm{MWCNT}$ could be well retained after 100 cycles at a relatively high current density of $1 \mathrm{~A} \mathrm{~g}^{-1}$, indicating good structure stability, leading to better cycling stability and rate performance.

To directly visualize the three-dimensional porous network formed and preserved during cycling, annular dark-field STEM (ADF-STEM) tomography was performed on $\mathrm{Co}_{1.5} \mathrm{Fe}_{1.5} \mathrm{O}_{4}$ particles at three specified states of charge. In Figure 1c, the consecutive cross-sectional images of the as-prepared $\mathrm{Co}_{1.5} \mathrm{Fe}_{1.5} \mathrm{O}_{4}$ particle clearly shows the shell wall has a solid structure. At the fully lithiated state, the particle retain the spherical shape while the shell wall becomes a perforated network (Figure 4f, and supplementary Movie 2). The hollow structure is still preserved; while with smaller voids inside the particle (the magenta isosurfaces in Figure $4 \mathrm{~h}$ render the voids inside the particle). Quantification shows that the volume fraction of the internal voids drops from $28.8 \%$ in the as-prepared state to $5.8 \%$ when it is fully lithiated. The decrease of the internal void volume demonstrates that indeed the hollow structure can buffer the volume expansion of the materials from within. After delithiation, the internal voids in the particle can be partially recovered - the internal voids' volume fraction increase from $5.8 \%$ to $12.3 \%$ (Figure $4 \mathrm{~h}$ and $4 \mathrm{i}$ ). While there were two small volumes of materials returned to solid form as indicated by the arrows in Figure 4g, the primary part of the materials retain a nanoporous structure (Supplementary Movie 3). The preservation of the nanoporous structure after delithiation can likely improve the ionic/electronic diffusivity and result in a decrease of the reaction resistance. These observations reveal the excellent structural flexibility of $\mathrm{Co}_{1.5} \mathrm{Fe}_{1.5} \mathrm{O}_{4}$ hollow particles. The interconnected porous in the 
particles not only increase the surface area, but also shorter the transport length for Li ions during lithiation/delithiation, favoring cycling stability and high-rate capability.

In summary, we have developed a simple and scalable strategy for the synthesis of hollow structured Co-Fe binary oxide for lithium-ion battery applications. A reversible capacity of 1233 and $1027 \mathrm{mAh} \mathrm{g}^{-1}$ can be retained over 500 cycles at a current density of $1 \mathrm{~A}$ $\mathrm{g}^{-1}$ for $\mathrm{Co}_{2} \mathrm{FeO}_{4} / \mathrm{MWNCT}$ and $\mathrm{Co}_{1.5} \mathrm{Fe}_{1.5} \mathrm{O}_{4} / \mathrm{MWCNT}$, respectively. Even when cycled at 5 and $8 \mathrm{~A} \mathrm{~g}^{-1}$, comparable capacities of 706 and $567 \mathrm{mAh} \mathrm{g}^{-1}$ could still be achieved on $\mathrm{Co}_{1.5} \mathrm{Fe}_{1.5} \mathrm{O}_{4} / \mathrm{MWCNT}$ electrode, showing a superior rate capability. Furthermore, $\mathrm{Co}_{2} \mathrm{FeO}_{4} / \mathrm{MWNCT}$ and $\mathrm{Co}_{1.5} \mathrm{Fe}_{1.5} \mathrm{O}_{4} / \mathrm{MWCNT}$ exhibit ultra-long cycling stability. They can maintain a capacity of 413.8 and $487.3 \mathrm{mAh} \mathrm{g}^{-1}$ up to 1000 cycles at a high current density of $5 \mathrm{~A} \mathrm{~g}^{-1}$. The superior cycling performance and rate capability of $\mathrm{Co}_{\mathrm{x}} \mathrm{Fe}_{3-\mathrm{x}} \mathrm{O}_{4} / \mathrm{MWCNT}(\mathrm{x}=2$, 1.5) electrodes resulted from enhanced electronic conductivity and sufficient void spaces that mitigate volume expansion as visualized by state-of-the-art electron tomography. The facile synthetic strategy provides insight for future mass production of high surface area metal oxides for large format battery applications.

\section{Acknowledgements}

This work was supported by the National Natural Science Foundation (21306060, 21573083), the Program for New Century Excellent Talents in Universities of China (NCET-13-0237), the Doctoral Fund of Ministry of Education of China (20130142120039), the Fundamental Research Funds for the Central University (2013TS136, 2014YQ009). We thank Analytical and Testing Center of Huazhong University of Science and Technology for allowing us to use its facilities. This research used resources of the Center for Functional Nanomaterials, which is a U.S. DOE Office of Science Facility, at Brookhaven National Laboratory under Contract No. DE-SC0012704. 


\section{Appendix A. Supporting information}

Supplementary data associated with this article can be found in the online version at http://dx.doi.org

\section{References}

[1] L. Qie, W. M. Chen, Z. H. Wang, Q. G. Shao, X. Li, L. X. Yuan, X. L. Hu, W. X. Zhang, Y. H. Huang, Adv. Mater., 24 (2012) 2047-2050.

[2] E. Yoo, J. Kim, E. Hosono, H.-s. Zhou, T. Kudo, I. Honma, Nano Lett., 8 (2008) $2277-$ 2282.

[3] P. Poizot, S. Laruelle, S. Grugeon, L. Dupont, J. Tarascon, Nature, 407 (2000) 496-499.

[4] B. Wang, H. L. Xin, X. D. Li, J. L. Cheng, G. C. Yang, F. D. Nie, Sci. Rep., 4 (2014) 3729-3736.

[5] Z. Wang, L. Zhou, Adv. Mater., 24 (2012) 1903-1911.

[6] N. Liu, H. Wu, M. T. McDowell, Y. Yao, C. Wang, Y. Cui, Nano Lett., 12 (2012) 33153321.

[7] Y. J. Lee, Y. Lee, D. Oh, T. Chen, G. Ceder, A. M. Belcher, Nano Lett., 10 (2010) 2433 2440.

[8] N. Mahmood, C. Zhang, Y. Hou, Small, 9 (2013), 1321-1328.

[9] M. Reddy, G. Subba Rao, B. Chowdari, Chem. Rev., 113 (2013) 5364-5457.

[10] G. Yang, H. Cui, G. Yang, C. Wang, ACS Nano, 8 (2014) 4474-4487.

[11] P.-L. Taberna, S. Mitra, P. Poizot, P. Simon, J.-M. Tarascon, Nat. Mater., 5 (2006) $567-$ 573. 
[12] F. Wang, R. Robert, N. A. Chernova, N. Pereira, F. Omenya, F. Badway, X. Hua, M. Ruotolo, R. G. Zhang, L. J. Wu, V. Volkov, D. Su, B. Key, M. S. Whittingharn, C. P. Grey, G. G. Amatucci, Y. M. Zhu, J. Graetz, J. Am. Chem. Soc., 133 (2011) 18828-18836.

[13] V. Etacheri, R. Marom, R. Elazari, G. Salitra, D. Aurbach, Energy Environ. Sci., 4 (2011) $3243-3262$

[14] W. M. Zhang, X. L. Wu, J. S. Hu, Y. G. Guo, L. J. Wan, Adv. Funct. Mater., 18 (2008) 3941-3946.

[15] J. Chen, X.-h. Xia, J.-p. Tu, Q.-q. Xiong, Y.-X. Yu, X.-1. Wang, C.-d. Gu, J. Mater. Chem., 22 (2012) 15056-15061.

[16] D. Gu, W. Li, F. Wang, H. Bongard, B. Spliethoff, W. Schmidt, C. Weidenthaler, Y. Xia, D. Zhao, F. Schuth, Angew. Chem., 54 (2015) 7060-7064.

[17] C. C. Li, Q. H. Li, L. B. Chen, T. H. Wang, J. Mater. Chem., 21 (2011) 11867-11872.

[18] D. L. Wang, Y. C. Yu, H. He, J. Wang, W. D. Zhou, H. D. Abruna, ACS Nano, 9 (2015) 1775-1781.

[19] L. Zhuo, Y. Wu, J. Ming, L. Wang, Y. Yu, X. Zhang, F. Zhao, J. Mater Chem. A, 1 (2013) 1141-1147.

[20] M. Dai, L. Song, J. T. LaBelle, B. D. Vogt, Chem. Mater., 23 (2011) 2869-2878.

[21] Z.-S. Wu, W. Ren, L. Wen, L. Gao, J. Zhao, Z. Chen, G. Zhou, F. Li, H.-M. Cheng, ACS Nano, 4 (2010) 3187-3194.

[22] P. Xiong, L. Peng, D. Chen, Y. Zhao, X. Wang and G. Yu, Nano Energy, 12 (2015), 816823. 
[23] P. Xiong, B. Liu, V. Teran, Y. Zhao, L. Peng, X. Wang and G. Yu, ACS Nano, 9 (2014), 8610-8616.

[24] L. Peng, X. Peng, B. Liu, C. Wu, Y. Xie and G. Yu, Nano Lett., 13 (2013), 2151-2157.

[25] L. Yu, L. Zhang, H. B. Wu, G. Zhang, X. W. Lou, Energy Environ. Sci., 6 (2013) 26642671.

[26] L. F. Shen, L. Yu, X. Y. Yu, X. G. Zhang, X. W. Lou, Angew. Chem., 54 (2015) 18681872.

[27] Z. H. Li, T. P. Zhao, X. Y. Zhan, D. S. Gao, Q. Z. Xiao, G. T. Lei, Electrochim. Acta., 55 (2010) 4594-4598.

[28] Z. Deng, M. Chen, G. Gu, L. Wu, J. Phys. Chem. B, 112 (2008) 16-22.

[29] F. Zou, X. Hu, Z. Li, L. Qie, C. Hu, R. Zeng, Y. Jiang, Y. Huang, Adv. Mater., 26 (2014) $6622-6628$.

[30] G. Zhang, L. Yu, H. B. Wu, H. E. Hoster, X. W. D. Lou, Adv. Mater., 24 (2012) 46094613.

[31] B. Wang, J. S. Chen, H. B. Wu, Z. Wang, X. W. Lou, J. Am. Chem. Soc., 133 (2011) 17146-17148.

[32] J. M. Jeong, B. G. Choi, S. C. Lee, K. G. Lee, S. J. Chang, Y. K. Han, Y. B. Lee, H. U. Lee, S. Kwon, G. Lee, Adv. Mater., 25 (2013) 6250-6255.

[33] G. Zhang, X. W. D. Lou, Angew. Chem., 126 (2014) 9187-9190.

[34] J. Wang, N. Yang, H. Tang, Z. Dong, Q. Jin, M. Yang, D. Kisailus, H. Zhao, Z. Tang, D. Wang, Angew. Chem., 125 (2013) 6545-6548. 
[35] X. W. Lou, C. M. Li, L. A. Archer, Adv. Mater., 21 (2009) 2536-2539.

[36] X. Sun, J. Liu, Y. Li, Chem. A Eur. J., 12 (2006) 2039-2047.

[37] J. Wang, H. L. Xin, J. Zhu, S. Liu, Z. Wu, D. Wang, J. Mater Chem. A, 3 (2015) 16011608.

[38] B. D. Anderson, J. B. Tracy, Nanoscale, 6 (2014) 12195-12216.

[39] Z. Wang, D. Luan, S. Madhavi, Y. Hu, X. W. D. Lou, Energy Environ. Sci., 5 (2012) $5252-5256$.

[40] L. Zhang, G. Zhang, H. B. Wu, L. Yu, X. W. D. Lou, Adv. Mater., 25 (2013) 2589-2593.

[41] N. A. Kaskhedikar, J. Maier, Adv. Mater., 21 (2009) 2664-2680.

[42] Y. Fang, Y. Y. Lv, R. C. Che, H. Y. Wu, X. H. Zhang, D. Gu, G. F. Zheng, D. Y. Zhao, J. Am. Chem. Soc., 135 (2013) 1524-1530.

[43] S. Ko, J. I. Lee, H. S. Yang, S. Park, U. Jeong, Adv. Mater., 24 (2012) 4451-4456.

[44] C. Masarapu, V. Subramanian, H. Zhu, B. Wei, Adv. Funct. Mater., 19 (2009) 10081014.

[45] M. V. Reddy, T. Yu, C. H. Sow, Z. X. Shen, C. T. Lim, G. V. Subba Rao, B. V. R. Chowdari, Adv .Funct. Mater., 17 (2007) 2792-2799.

[46] L. Yin, Z. Zhang, Z. Li, F. Hao, Q. Li, C. Wang, R. Fan, Y. Qi, Adv .Funct. Mater., 24 (2014) 4176-4185.

[47] J. Bai, X. Li, G. Liu, Y. Qian, S. Xiong, Adv .Funct. Mater., 24 (2014) 3012-3020. 
[48] J. Lin, A.-R. O. Raji, K. Nan, Z. Peng, Z. Yan, E. L. G. Samuel, D. Natelson, J. M. Tour, Adv .Funct. Mater., 24 (2014) 2044-2048.

[49] S. Liu, J. Xie, C. Fang, G. Cao, T. Zhu, X. Zhao, J. Mater. Chem., 22 (2012) 1973819743.

[50] A. K. Rai, J. Gim, T. V. Thi, D. Ahn, S. J. Cho, J. Kim, J. Phys. Chem. C, 118 (2014) 11234-11243.

[51] L. Zhang, H. B. Wu, S. Madhavi, H. H. Hng, X. W. Lou, J. Am. Chem. Soc., 134 (2012) 17388-17391.

[52] F. Lin, D. Nordlund, T.-C. Weng, Y. Zhu, C. Ban, R. M. Richards, H. L. Xin, Nat. Commun., 5 (2014) 4358-4397. 
(a)

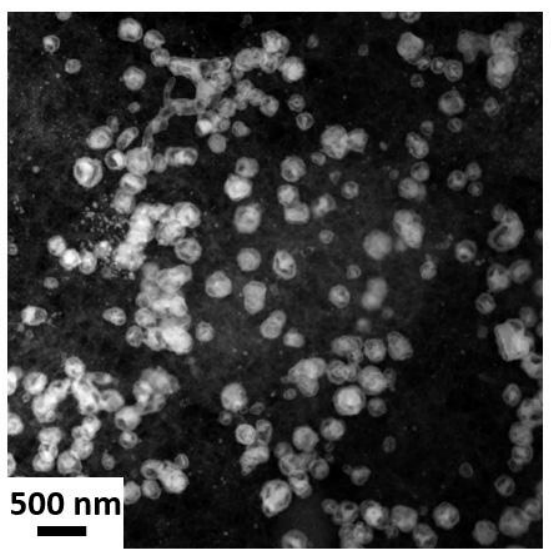

(c)

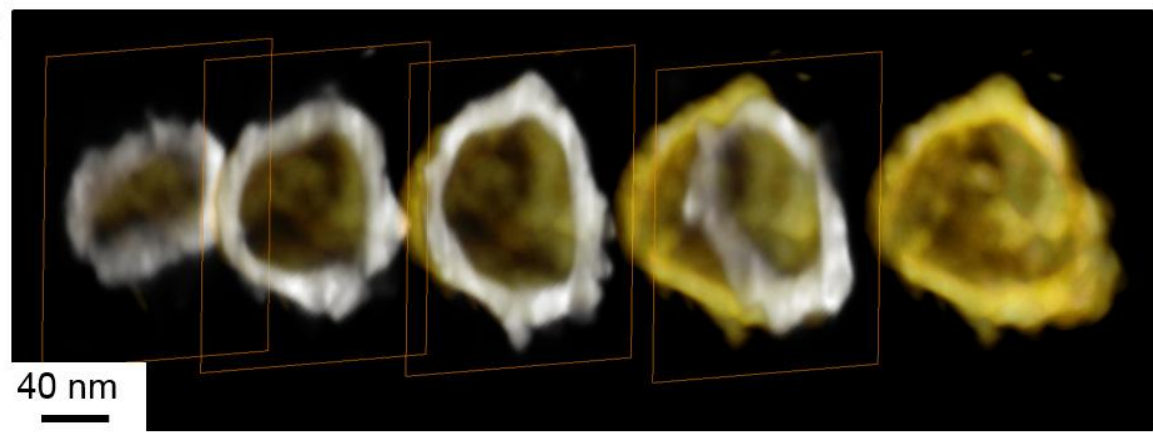

(d)

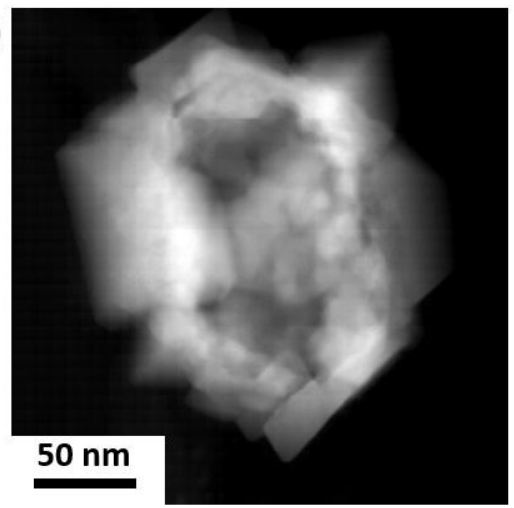

(b)

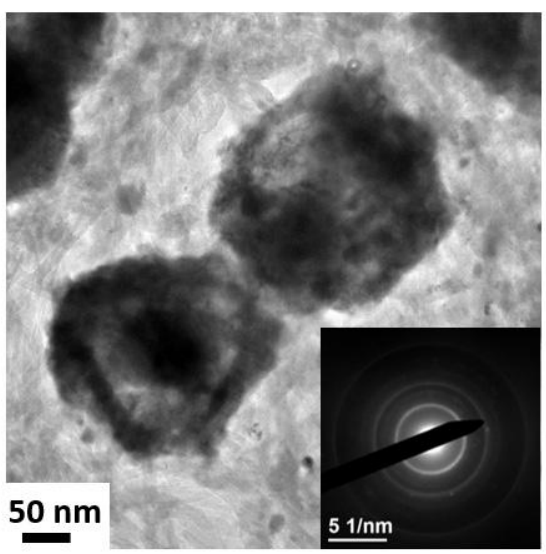

$50 \mathrm{~nm}$
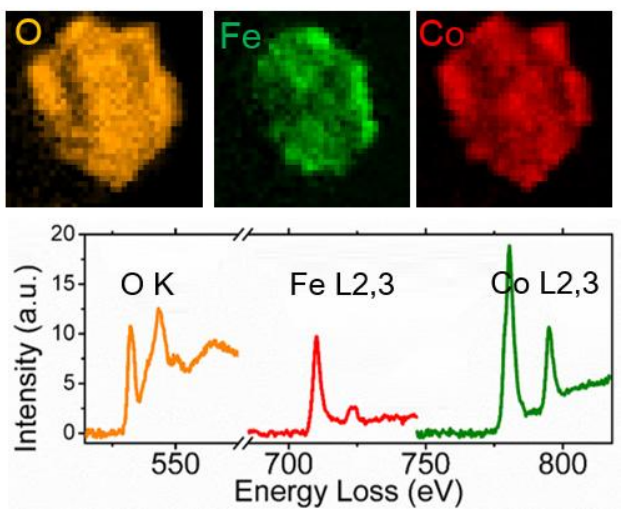

Figure 1. (a) Z-contrast STEM and (b) BF-STEM image of $\mathrm{Co}_{1.5} \mathrm{Fe}_{1.5} \mathrm{O}_{4} / \mathrm{MWCNT}$ hollow spheres. Inset of (b): the corresponding selected area electron diffraction (SAED) pattern. (c) 3-D tomographic reconstruction of the as-prepared $\mathrm{Co}_{1.5} \mathrm{Fe}_{1.5} \mathrm{O}_{4}$ hollow particles. (d) EELS element mapping and $\mathrm{O}$ K-edge, $\mathrm{Fe} \mathrm{L}_{2,3}$-edge and $\mathrm{Co} \mathrm{L}_{2,3}$-edge spectra for a $\mathrm{Co}_{1.5} \mathrm{Fe}_{1.5} \mathrm{O}_{4}$ hollow particle. 

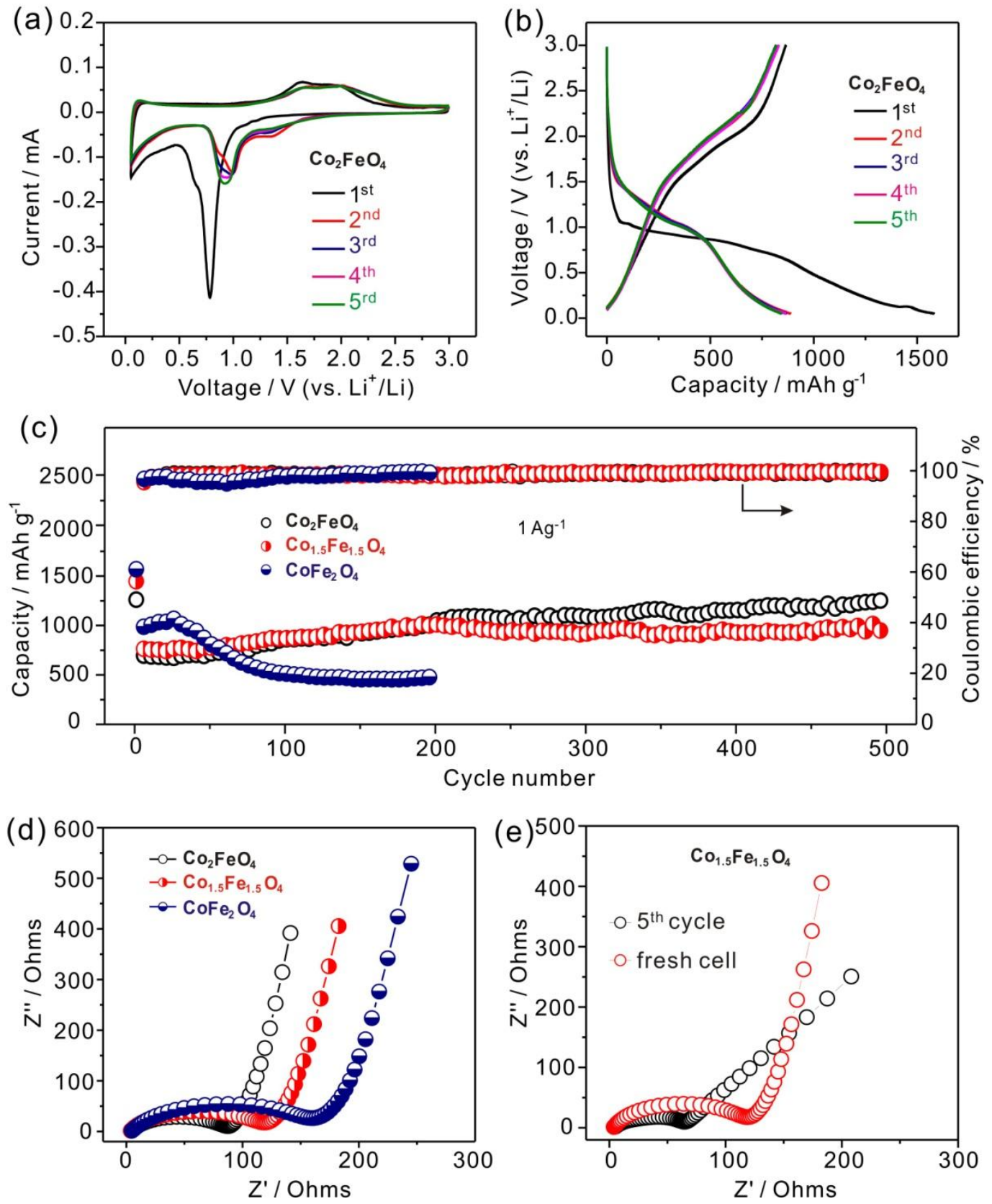

Figure 2. (a) $\mathrm{CV}$ curves of the $\mathrm{Co}_{2} \mathrm{FeO}_{4} / \mathrm{MWNCT}$ electrode at a scan rate of $0.1 \mathrm{mV} \mathrm{s}^{-1}$. (b) discharge/charge profiles of the $\mathrm{Co}_{2} \mathrm{FeO}_{4} / \mathrm{MWNCT}$ electrode at a current density of $0.1 \mathrm{~A} \mathrm{~g} \mathrm{~g}^{-1}$. (c) Cycling performance of $\mathrm{Co}_{\mathrm{x}} \mathrm{Fe}_{3-\mathrm{x}} \mathrm{O}_{4} / \mathrm{MWCNT}$ electrodes and correspond Coulombic 
efficiency at a current density of $1 \mathrm{~A} \mathrm{~g} \mathrm{~g}^{-1}$. (d, e) Nyquist plots of $\mathrm{Co}_{\mathrm{x}} \mathrm{Fe}_{3-\mathrm{x}} \mathrm{O}_{4} / \mathrm{MWCNT}$ electrodes before and after 5 cycles.
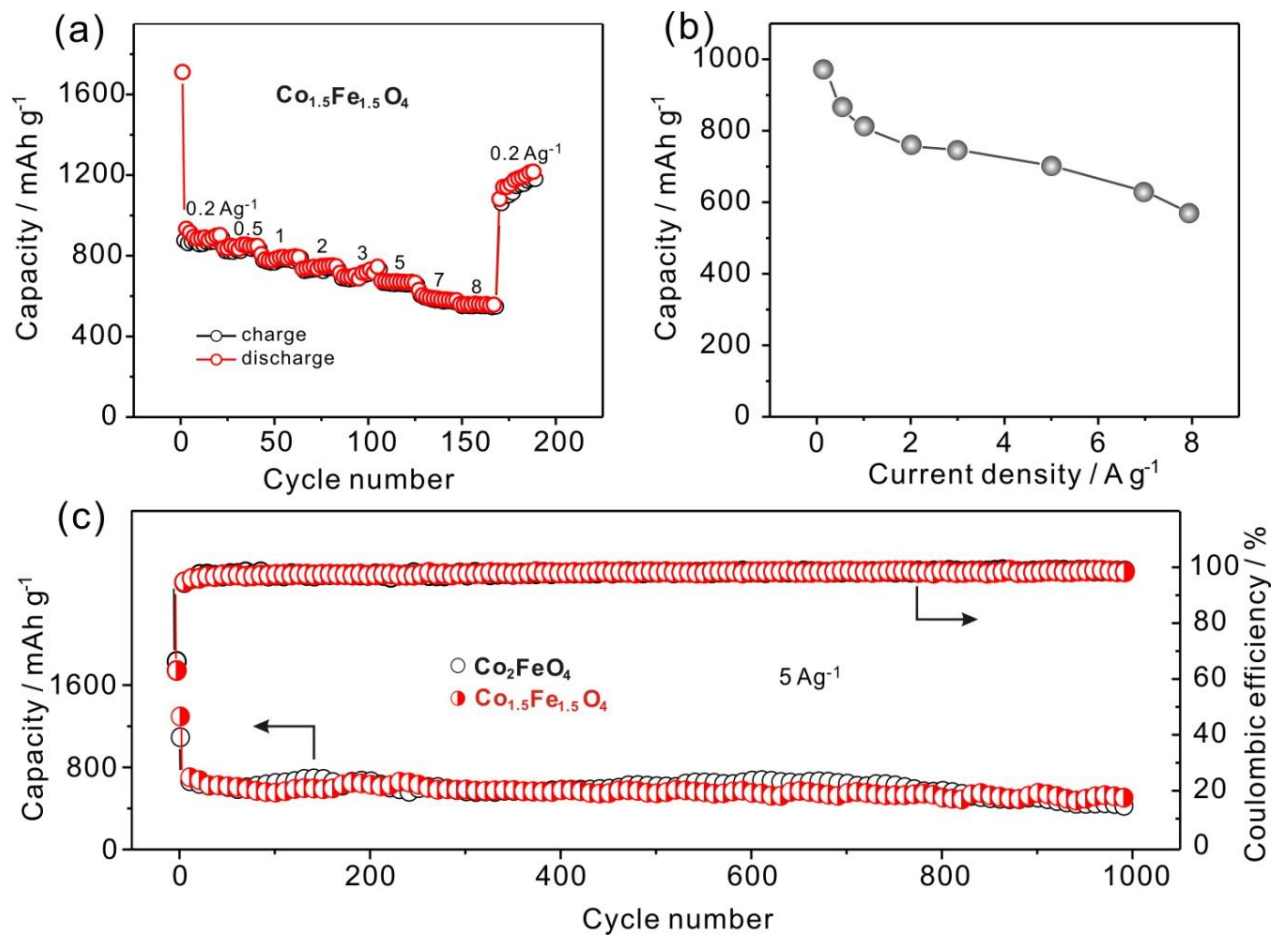

Figure 3. (a) Rate performance of $\mathrm{Co}_{1.5} \mathrm{Fe}_{1.5} \mathrm{O}_{4} / \mathrm{MWCNT}$ hollow spheres electrodes at various current densities from $0.2 \mathrm{~A} \mathrm{~g}^{-1}$ to $8 \mathrm{~A} \mathrm{~g}^{-1}$. (b) The current density dependence of the discharge capacity for $\mathrm{Co}_{1.5} \mathrm{Fe}_{1.5} \mathrm{O}_{4} / \mathrm{MWCNT}$. (c) Cycling performance of $\mathrm{Co}_{\mathrm{x}} \mathrm{Fe}_{3-}$ ${ }_{\mathrm{x}} \mathrm{O}_{4} / \mathrm{MWCNT}$ electrodes $(\mathrm{x}=2,1.5)$ and corresponding Coulombic efficiency at a current density of $5 \mathrm{~A} \mathrm{~g}^{-1}$. 


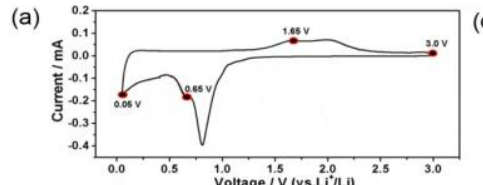

(b)
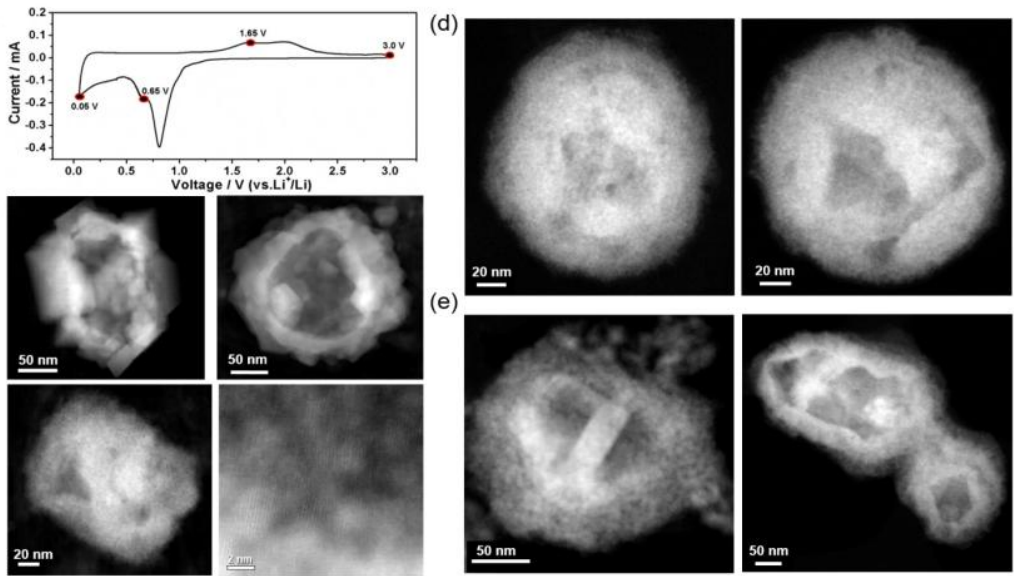

(c)
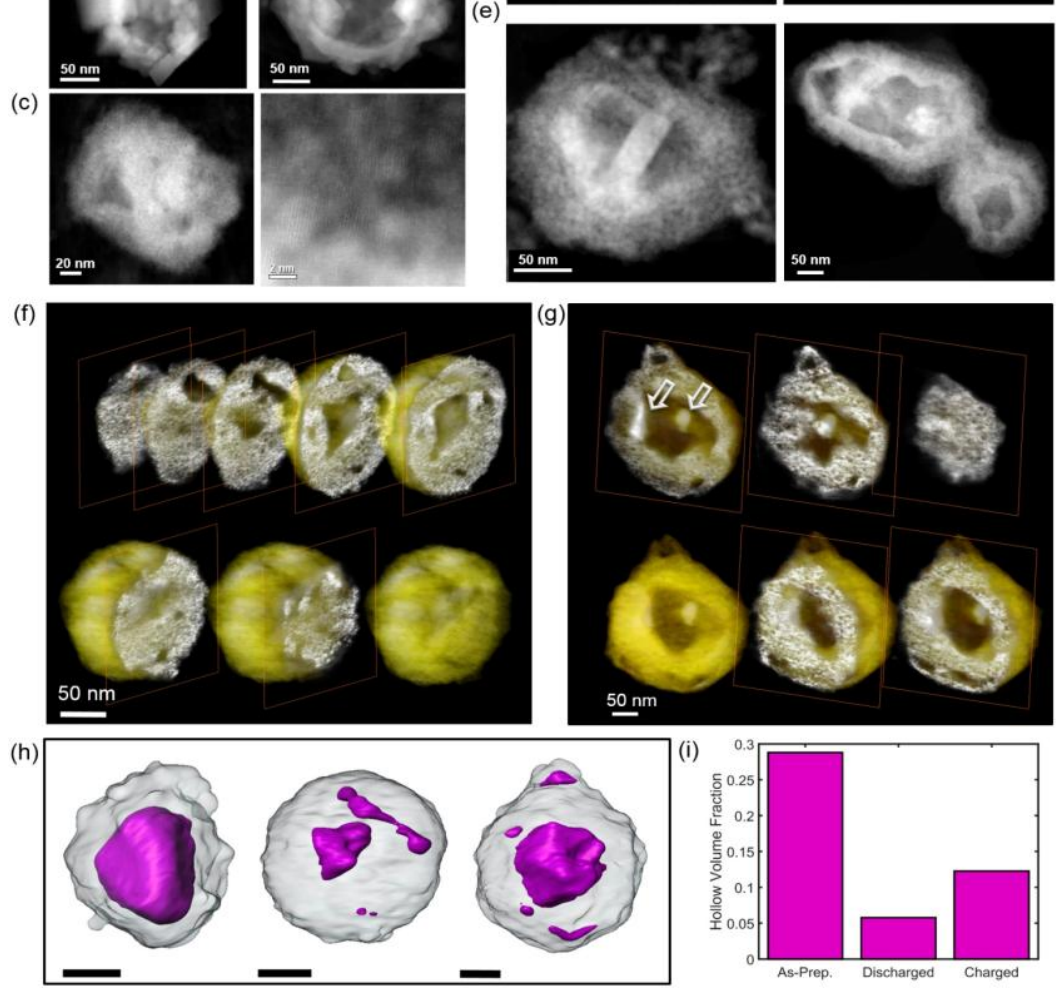

Figure 4. Z-contrast STEM image and 3-D tomographic reconstruction of $\mathrm{Co}_{1.5} \mathrm{Fe}_{1.5} \mathrm{O}_{4} / \mathrm{MWCNT}$ particles obtained at selected discharge/charge states. (a) Voltagecomposition trace for $\mathrm{Co}_{1.5} \mathrm{Fe}_{1.5} \mathrm{O}_{4} / \mathrm{MWCNT}$ cell cycled between 0.01 and $3.0 \mathrm{~V}$. (b-d) $\mathrm{Co}_{1.5} \mathrm{Fe}_{1.5} \mathrm{O}_{4} / \mathrm{MWCNT}$ particles at (b) as-prepared state, (c) half-discharged state, (d) fulldischarged state, and (e) full-charged state. (f) 3-D tomographic reconstruction of particle at fully discharged state. The shell becomes nanoporous and the internal voids have shrunk in volume fraction. (g) At fully charged state. The shell primarily remains nanoporous with two small volumes return to a solid form. The internal voids have grown in volume fraction compared with (f). (h and i) Quantification of the internal voids' volume fraction (left: asprepared, middle: fully discharged, right: fully charged). The internal voids (not the nanopores) are segmented and presented by magenta isosurfaces in (h). Scale bars: $50 \mathrm{~nm}$. (i) The quantified internal voids' volume fraction at the three states of charge. 


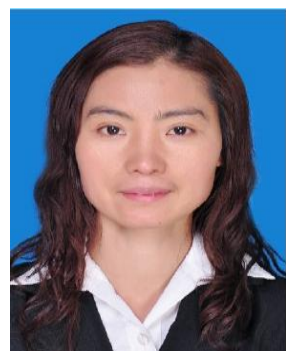

Deli Wang received her Ph.D. from Wuhan University in 2008. And then she joined in Nanyang Technological University working as a research fellow for 1 year. She moved to Cornell University in 2009, joined in Energy Materials Center at Cornell $\left(\mathrm{EMC}^{2}\right)$ as a postdoctoral associate for 3 years. In 2012, she came back to China. She is currently a professor of School of Chemistry and Chemical Engineering, Huazhong University of Science \& Technology (HUST). Her research interests mainly focused on nanomaterials for energy conversion and storage.

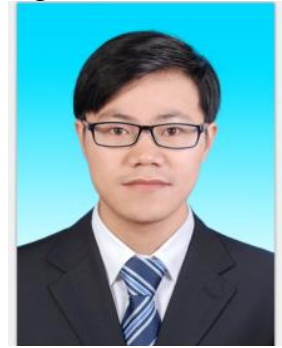

Huan He obtained his bachelor degree from Tianjin polytechnic University. He is currently pursuing his Master's degree in the School of Chemistry and Chemical Engineering at Huazhong University of Science and Technology. His present research interest mainly focus on anode materials for lithium-ion batteries.

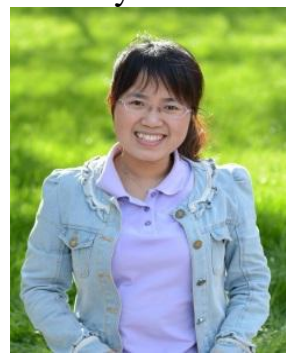

Lili Han obtained her Master's degree in Materials Science from Tianjin University in China. In 2012, she started her PhD study in the Quantum Dot Materials and Devices Research Group at Tianjn University in China, under the supervision of Prof. Xi-wen Du. In September 2014, she joined Dr. Huolin Xin's group in the Center for Functional Nanomaterials at Brookhaven National Laboratory (BNL) as an exchange Ph.D. student. Her research at BNL focuses on characterization of nanocatalysts using in-situ and analytical electron microscopy.

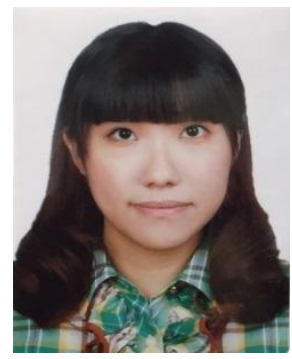

Ruoqian Lin obtained her Master's degree in Materials Science from Stony Brook University. She is currently a Ph.D. student in the City University of New York. 


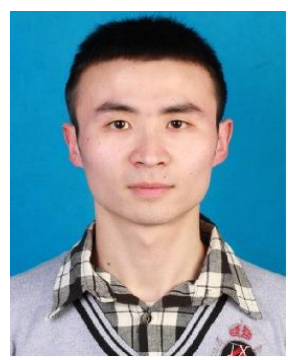

Jie Wang obtained his bachelor degree from Qingdao Agricultural University. He is currently pursuing his Ph.D in the School of Chemistry and Chemical Engineering at Huazhong University of Science and Technology (HUST), under the supervision of Prof. Deli Wang. His present research interests focus on synthesis of hollow structured $3 \mathrm{~d}$ transition metal oxides and its application in energy conversion and storage.

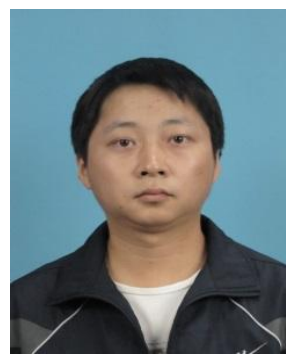

Zexing Wu received his B.S. from Binzhou University. He is a Ph.D. candidate in the School of Chemistry and Chemical Engineering at Huazhong University of Science and Technology (HUST). His present research interest mainly focus on through polymer and solvothermal methods to prepare electrocatalysts.

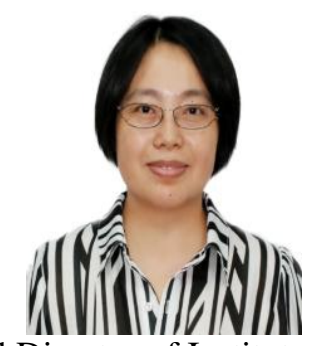

Hongfang Liu is currently a Professor and Director of Institute of Materials and Environmental Chemistry, School of Chemistry and Chemical Engineering, Huazhong University of Science and Technology(HUST). She received her PhD from HUST in 2000. And then she worked as an associated professor for 3 years. In 2003, she joined in Hiroshima University as a visiting professor in Venture Business Laboratory. After 2 years she came back to HUST. Her research interests mainly focused on nano functional materials and applications, material service failure.

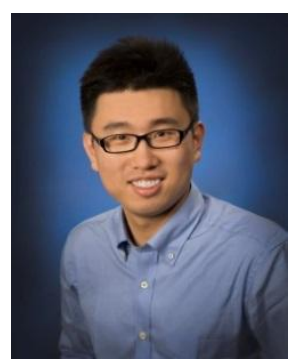

Huolin Xin is a staff scientist in the Center for Functional Nanomaterials at Brookhaven National Laboratory. He is also an adjunct faculty member at Stony Brook University. His primary field of expertise lies in developing novel 3-D, atomic-resolution, and in-situ spectroscopic and imaging tools to probe the structural, chemical, and bonding changes of energy materials during chemical reactions or under external stimuli. 
Cover page

Click here to download high resolution image

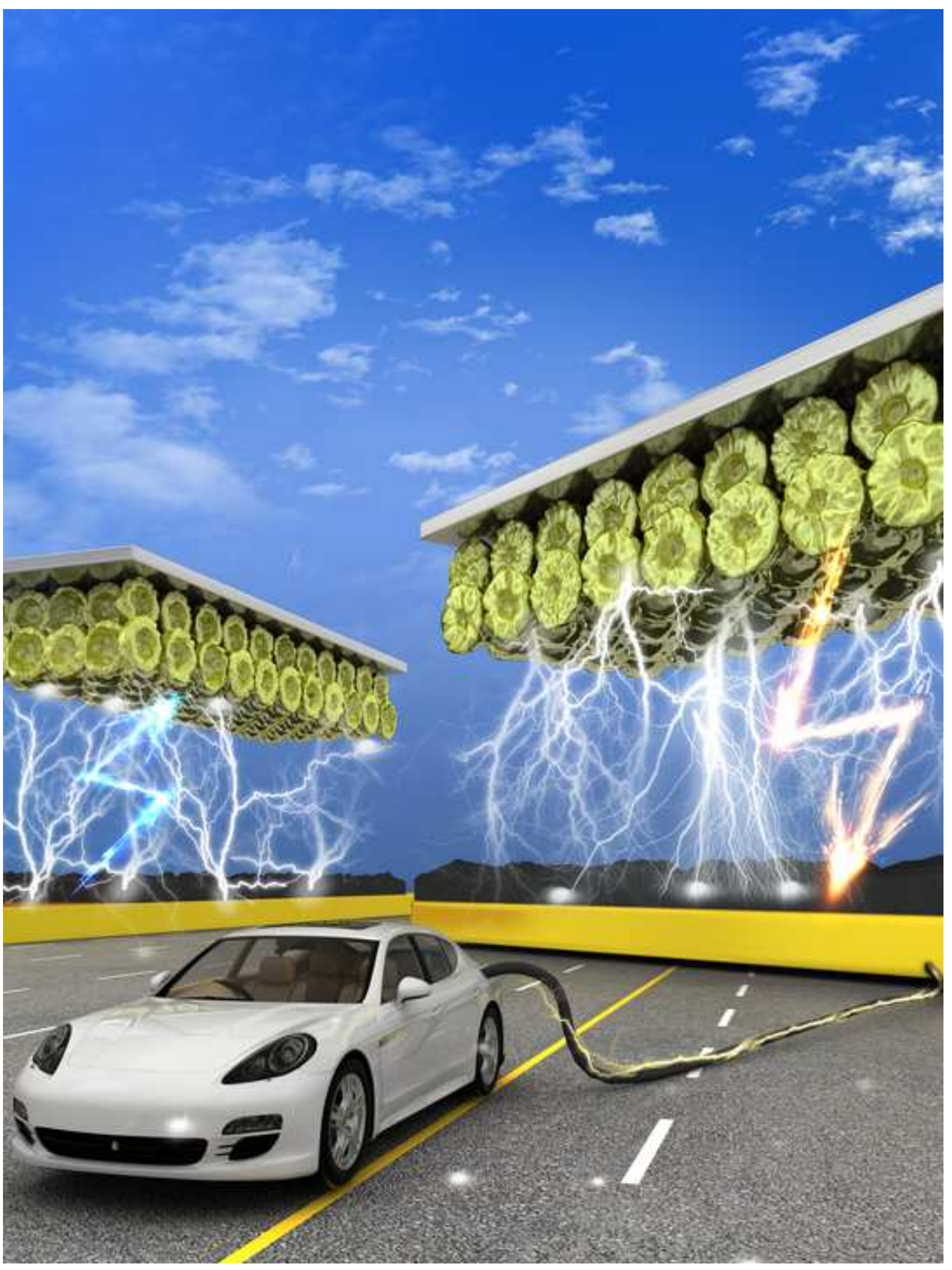




\section{Graphical Abstract}

Using state-of-the-art electron tomography, we directly visualize hollow structured $\mathrm{Co}_{\mathrm{x}} \mathrm{Fe}_{3-\mathrm{x}} \mathrm{O}_{4}$ nanoparticles, where the voids serve to buffer the volume expansion of the material. The unique structure results in a high reversible capacity as well as an outstanding rate performance and long-term cycling stability for lithium-ion battery.

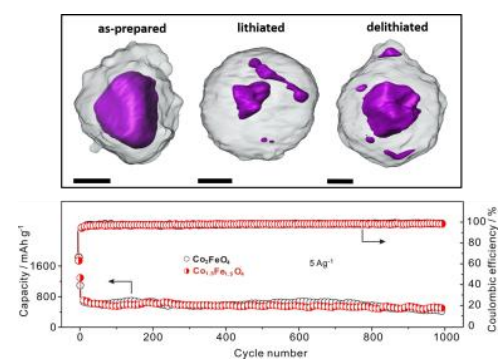

